\title{
MEASUREMENT OF VISCOSITY USES AN ALTERNATIVE VISCOMETER
}

\author{
Oktabella Regina $^{* 1)}$, Hendar Sudrajad ${ }^{2)}$, Dina Syaflita ${ }^{3)}$ \\ ${ }^{1,2,3)}$ Physics Education, University of Riau \\ e-mail: 3010regina@gmail.com \\ hendarsudrajad61@gmail.com \\ dinasyaflita@yahoo.com
}

\begin{abstract}
Physics learning for fluids can be done by practical methodes in orther the students really understand about the fluids concepts. One of the fluids learning that needs to be practice is about viscosity. Measuring instrument used to determine the viscosity of a liquid is a viscometer. This viscosity measuring instrument can measure the thickness of a fluids accurately and specifically in accordance with predetermined standards. Due to the importance of the amount of viscosity, it is necessary to know the measurement method easily, cheaply and thoroughly. One way that can be used is to use an alternative viscometer as a measure of fluids viscosity. The purpose of this research is to produce an alternative viscometer that can measure the viscosity of a fluids. The type of this research is research and development, namely developing and measuring with an alternative viscometer. This research results that the measurement with an alternative viscometer for several liquids with different viscosity, gets a value that is not much different from the standard viscosity measurement results. The conclusion of the results of this research is that an alternative viscometer can be used to determine the viscosity of a liquid.
\end{abstract}

Keywords: fluids, viscometer, viscosity

\section{PENGUKURAN VISKOSITAS MENGGUNAKAN VISKOMETER ALTERNATIF}

\author{
Oktabella Regina $^{* 1)}$, Hendar Sudrajad ${ }^{2)}$, Dina Syaflita ${ }^{3)}$ \\ ${ }^{1,2,3)}$ Pendidikan Fisika, Universitas Riau
}

\begin{abstract}
Abstrak
Pembelajaran Fisika untuk materi fluida dapat dilakukan dengan metode praktikum agar peserta didik benarbenar memahami konsep fluida. Salah satu pembelajaran fluida yang perlu dipraktekkan adalah materi viskositas (kekentalan). Alat ukur yang digunakan untuk menentukan viskositas suatu zat cair adalah viskometer. Alat ukur kekentalan ini dapat mengukur tingkat kekentalan suatu zat cair dengan akurat dan spesifik sesuai dengan standar yang telah ditentukan. Berhubung pentingnya besaran viskositas, maka perlu diketahui metode pengukurannya secara mudah, murah, dan teliti. Salah satu cara yang dapat digunakan adalah menggunakan viskometer alternatif sebagai alat ukur kekentalan zat cair. Tujuan dari penelitian ini adalah untuk menghasilkan viskometer alternatif yang dapat mengukur viskositas suatu zat cair. Jenis penelitian adalah penelitian pengembangan, yaitu mengembangkan dan melakukan pengukuran dengan viskometer alternatif. Penelitian ini memberikan hasil bahwa pengukuran dengan viskometer alternatif terhadap beberapa zat cair yang berbeda kekentalannya, mendapatkan nilai yang tidak jauh berbeda dengan hasil pengukuran viskositas standar. Kesimpulan dari hasil penelitian ini bahwa viskometer alternatif dapat digunakan untuk menentukan viskositas suatu zat cair.
\end{abstract}

Kata kunci: fluida, viskometer, viskositas

1) Komunikasi Penulis 


\section{Pendahuluan}

Fisika merupakan disiplin ilmu alam yang mempelajari tentang gejala alam. Salah satu gejala alam yang menjadi kajian ilmu Fisika di sekolah adalah fluida. Fluida adalah zat yang dapat mengalir. Fluida menyesuaikan diri dengan bentuk wadah apapun dimana kita menempatkannya. Fluida bersifat demikian karena tidak dapat menahan gaya yang bersinggungan dengan permukaannya (Halliday, 2012).

Karakteristik-karakteristik tertentu dari suatu fluida tidak bergantung kepada gerakan fluida. Tetapi bergantung pada sifat alamiah fluida itu sendiri. Salah satu sifat yang menjadi karakteristik fluida adalah sifat kekentalan (viscous) dimana setiap fluida memiliki koefisien kekentalan yang berbeda-beda. Viskositas dapat dinyatakan sebagai tahanan aliran fluida yang merupakan gesekan antara molekul-molekul cairan satu dengan yang lain. Suatu jenis cairan yang mudah mengalir, dapat dikatakan memiliki viskositas yang rendah, dan sebaliknya bahan yang sulit mengalir dikatakan memiliki viskositas yang tinggi (Samdara, 2008).

Alat ukur yang digunakan untuk menentukan kekentalan (viskositas) suatu zat cair adalah viskometer. Alat ukur kekentalan ini dapat mengukur tingkat kekentalan suatu zat cair dengan akurat dan spesifik sesuai dengan standar yang telah ditentukan. Apabila volume zat cair yang mengalir melalui penampang per satuan waktu disebut dengan debit (Q), maka sesuai persamaan Poiseuille dipenuhi:

$$
\mathrm{Q}=\frac{\pi \mathrm{r}^{4} \Delta \mathrm{P}}{8 \eta \eta}
$$

atau

$$
\mathrm{Q}=\frac{\pi \mathrm{d}^{4} \Delta \mathrm{P}}{128 \eta 2}
$$

dengan $\mathrm{Q}$ adalah volume cairan yang mengalir perdetik $\left(\mathrm{m}^{3} / \mathrm{s}\right), \Delta \mathrm{P}$ beda tekanan antara ujungujung pipa $\left(\mathrm{N} / \mathrm{m}^{2}\right), \eta$ viskositas zat cair $\left(\mathrm{Ns} / \mathrm{m}^{2}\right)$, $\mathrm{r}$ jari-jari dalam penampang pipa $(\mathrm{m}), \mathrm{d}$ diameter dalam pipa $(\mathrm{m})$ dan $\mathrm{L}$ adalah panjang pipa (m). Jika zat cair yang diuji mempunyai viskositas $\eta_{1}$ maka pembandingnya (air) berviskositas $\eta_{2}$, dengan jari-jari $\mathrm{r}^{4}$, densitas $(\rho)$, waktu (t), volume (V), panjang pipa (L). Selanjutnya, hasil perbandingan kedua viskositas itu pada debit yang sama memenuhi persamaan (3) atau (4) (Sutiah, et al., 2008).

dan

$$
\frac{\eta_{1}}{\eta_{2}}=\frac{\pi r^{4}(\rho . t)_{1}}{8 V L} x \frac{8 V L}{\pi r^{4}(\rho . t)_{2}}
$$

$$
\frac{\eta_{1}}{\eta_{2}}=\frac{\rho_{1} t_{1}}{\rho_{2} t_{2}}
$$

Berhubung pentingnya besaran viskositas dalam kehidupan, maka perlu diketahui metode pengukurannya secara mudah, murah, dan teliti. Salah satu cara yang bisa digunakan adalah dengan menggunakan viskometer alternatif sebagai alat ukur kekentalan zat cair (Sutiah, et al., 2008). Satuan viskositas dalam SI ditetapkan dalam satuan $\mathrm{mm}^{2} / \mathrm{s}$ atau $\mathrm{cm}^{2} / \mathrm{s}$, dimana $1 \mathrm{~cm}^{2} / \mathrm{s}$ setara dengan $1 \mathrm{St}$ (Stokes) (Young, 2002). Satuan viskositas yang lain adalah Poise (P), $1 \mathrm{P}=1 \mathrm{Ns} / \mathrm{m}^{2}$. Adapun daftar nilai viskositas zat cair pada berbagai suhu dalam satuan ditunjukkan melalui Tabel 1.

Tabel 1. Nilai viskositas zat cair pada berbagai suhu (dalam Poise)

$\begin{array}{lllllrl}\text { Cairan } & \mathbf{0}^{\mathbf{0}} \boldsymbol{C} & \mathbf{1 0}^{\mathbf{0}} \boldsymbol{C} & \mathbf{2 0}^{\mathbf{}} \boldsymbol{C} & \mathbf{3 0}^{\mathbf{0}} \boldsymbol{C} & \mathbf{4 0}^{\mathbf{0}} \boldsymbol{C} & \mathbf{5 0}^{\mathbf{0}} \boldsymbol{C} \\ \text { Air } & 0,0179 & 0,013 & 0,0101 & 0,008 & 0,0065 & 0,0055 \\ \text { Gliserin } & 105,9 & 34,4 & 13,4 & 6,29 & 2,89 & 1,41 \\ \text { Amilin } & 0,102 & 0,065 & 0,0044 & 0,0316 & 0,0227 & 0,0185 \\ \text { Bensin } & 0,0091 & 0,0076 & 0,0065 & 0,0056 & 0,005 & 0,0044 \\ \text { Etanol } & 0,0177 & 0,0147 & 0,012 & 0,0100 & 0,0083 & 0,007 \\ \text { Minyak } & 25,3 & 3,84 & 1,63 & 0,96 & - & - \\ \text { Lobak } & & & & & & \end{array}$

Sumber: Bird dalam (Rana, 2015).

Viskometer merupakan alat pengukur kekentalan suatu fluida. Viskometer yang umum digunakan adalah viskometer peluru jatuh, viskometer tabung/kapiler/Ostwald, dan sistem rotasi (Ridwan, et al., 2012). Viskometer alternatif yang dibuat termasuk jenis viskometer Ostwald. Viskometer Ostwald merupakan salah satu jenis viskometer yang banyak digunakan. Viskometer Ostwald memerlukan sampel yang lebih sedikit dibandingkan viskometer yang lain (Mike dalam Putra, 2013). Prinsip yang digunakan adalah dengan mengukur waktu yang diperlu kan oleh cairan untuk melewati dua titik yang telah ditentukan pada sebuah tabung kapiler vertikal (Sinila, 2016). 
Viskometer Ostwald alternatif dapat digunakan untuk menentukan nilai viskositas zat cair yang belum diketahui nilainya. Penentuan nilai ini dilakukan dengan membandingkan nilai viskositas cairan pembanding yang sudah diketahui nilainya dengan cairan lain yang belum diketahui nilai viskositasnya (Sutiah, et al., 2008).

Viskometer alternatif digunakan untuk mendapatkan nilai viskositas dengan cara bekerja berdasarkan selang waktu yang dibutuhkan oleh sejumlah larutan tertentu untuk mengalir melalui gelas buret karena adanya gaya yang disebabkan oleh berat larutan itu sendiri. Maka dari itu, dengan dirancang dan dibangunnya viskometer alternatif ini, diharapkan untuk kita dapat menentukan nilai viskositas dari suatu zat cair. Adapun tujuan penelitian ini adalah untuk menghasilkan viskometer alternatif yang dapat mengukur viskositas suatu zat cair.

\section{Bahan dan Metode}

Penelitian dilaksanakan di Laboratorium Pendidikan Fisika FKIP Universitas Riau yang dimulai pada bulan Februari 2018 sampai bulan Mei 2018. Jenis penelitian termasuk penelitian pengembangan, yaitu mengembangkan dan melakukan pengukuran terhadap alat viskometer ostwalt alternatif yang dirancang. Alat yang diperlukan dalam pembuatan alat viskometer alternatif yaitu: 1) Akrilik, 2) Buret $50 \mathrm{ml}$, 3) Corong, 4) Penyangga, 5) Bak penampung, 6) Stopwatch, 7) Termometer.

Adapun bahan yang diperlukan adalah zat cair. Zat cair yang diambil untuk pengujian viskositas adalah air, minyak goreng, pertalite, dan bensin. Desain rancangan viskometer ostwald alternatif ditunjukkan pada Gambar 1.

Rangkaian penyusun pengukur viskositas zat cair terdiri dari buret, bak penampung, corong, serta stopwatch.

\section{a. Buret}

Buret adalah komponen penting pada alat ini yang digunakan sebagai tabung penampung zat cair yang akan diukur viskositasnya berdasarkan waktu alir zat cair tersebut. Buret diposisikan vertikal agar mempermudah zat cair mengalir diakibatkan oleh berat zat cair itu sendiri.

b. Bak Penampung

Bak penampung merupakan wadah yang digunakan untuk menampung zat cair yang mengalir keluar dari buret. Bak penampung diletakkan di bawah buret.

c. Corong

Corong berfungsi untuk memudahkan memasukkan zat cair ke dalam buret.

d. Stopwatch

Stopwatch berfungsi sebagai penunjuk waktu lamanya zat cair tersebut mengalir melewati buret.

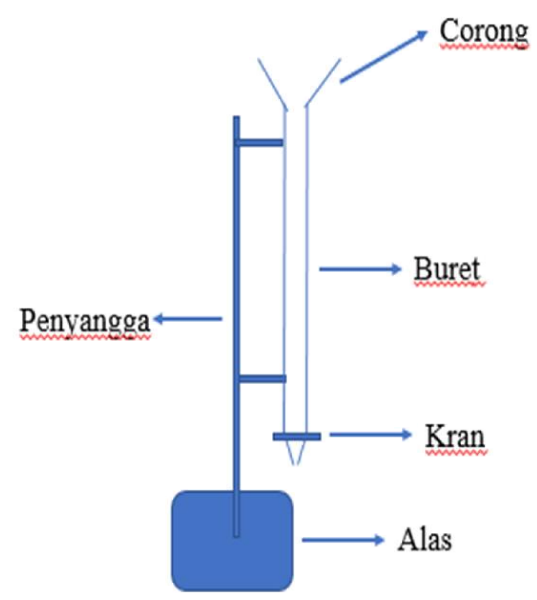

Gambar 1. Desain alat viskometer ostwald alternatif.

Keterangan:

1. Corong berfungsi untuk memudahkan memasukkan zat cair ke dalam buret.

2. Buret berfungsi sebagai tabung penampung zat cair yang akan diukur viskositasnya berdasarkan waktu alir zat cair tersebut.

3. Akrilik berfungsi sebagai penyangga buret.

4. Kran berfungsi sebagai penahan zat cair.

5. Akrilik berfungsi sebagai alas dari alat.

Nilai viskositas diperoleh dari data hasil pengukuran lamanya waktu alir suatu zat cair terhadap viskositas zat, dan penentuan viskositasnya menggunakan persamaan (4).

\section{Hasil dan Pembahasan}

Hasil rancangan alat viskometer Ostwald alternatif ditunjukkan oleh Gambar 2. Adapun 
hasil penelitian menunjukkan bahwa terdapat hubungan antara viskositas zat cair dengan lamanya waktu alir dari zat cair tersebut, hubungan keduanya yakni berbanding lurus, yang artinya semakin besar viskositas dari suatu zat cair, maka akan semakin besar waktu alirnya nya. Sebaliknya, semakin kecil viskositas suatu zat cair maka waktu alir dari zat cair tersebut akan semakin kecil.

Hasil pengujian alat pengukur viskositas zat cair didapatkan data lamanya waktu alir dengan variasi suhu dari masing-masing zat cair ditunjukkan pada Tabel 2, Tabel 3, dan Tabel 4.

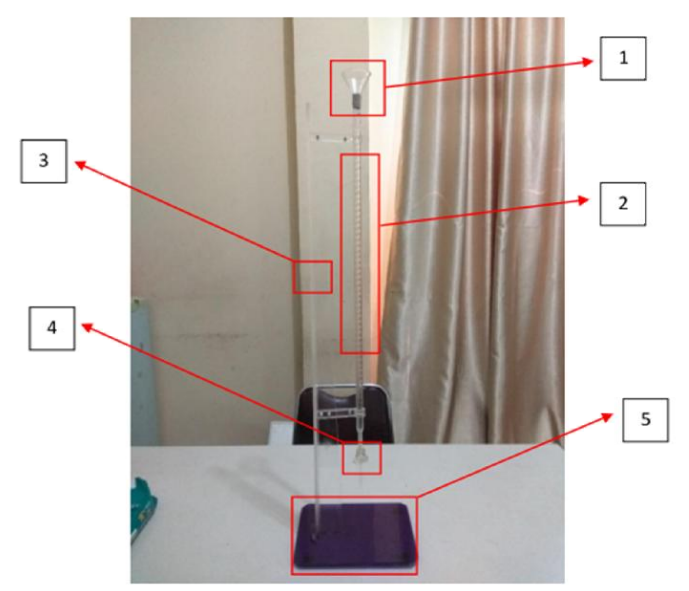

Gambar 2. Hasil rancangan viskometer ostwald alternatif.

Tabel 2. Data pengujian waktu alir viskositas zat cair pada suhu $27^{\circ} \mathrm{C}$

\begin{tabular}{llcrrrrrr}
\hline \multirow{2}{*}{ No } & Nama Zat Cair & \multirow{2}{*}{\begin{tabular}{c} 
Volume \\
\cline { 3 - 6 }
\end{tabular}} & \multicolumn{4}{c}{ Pengukuran Waktu (s) } & \multicolumn{1}{c}{$\begin{array}{c}\text { Rerata } \\
\text { Waktu }\end{array}$} \\
\cline { 5 - 7 } & & \multicolumn{1}{c}{ I } & \multicolumn{1}{c}{ II } & \multicolumn{1}{c}{ III } & \multicolumn{1}{c}{ IV } & \multicolumn{1}{c}{ V } & \multicolumn{1}{c}{ (s) } \\
\hline 1 & Air & 35 & 43,7 & 43,3 & 43,7 & 43,7 & 43,5 & 43,58 \\
2 & Minyak Goreng & 35 & 770,2 & 765,5 & 766,5 & 765,4 & 767,4 & 767,00 \\
3 & Pertalite & 35 & 41,4 & 41,5 & 41,6 & 41,5 & 41,7 & 41,54 \\
4 & Minyak Bensin & 35 & 47,9 & 48,2 & 48,2 & 48,0 & 48,1 & 48,08 \\
\hline
\end{tabular}

Tabel 3. Data pengujian waktu alir viskositas zat cair pada suhu $30^{\circ} \mathrm{C}$

\begin{tabular}{|c|c|c|c|c|c|c|c|c|}
\hline \multirow{2}{*}{ No } & \multirow{2}{*}{ Nama Zat Cair } & \multirow{2}{*}{$\begin{array}{c}\text { Volume } \\
(\mathrm{ml})\end{array}$} & \multicolumn{5}{|c|}{ Pengukuran Waktu (s) } & \multirow{2}{*}{$\begin{array}{c}\text { Rerata } \\
\text { Waktu } \\
\text { (s) }\end{array}$} \\
\hline & & & I & II & III & IV & $\mathrm{V}$ & \\
\hline 1 & Air & 35 & 42,9 & 43,5 & 43,7 & 43,1 & 43,0 & 43,24 \\
\hline 2 & Minyak Goreng & 35 & 501,6 & 501,8 & 502,0 & 501,5 & 501,5 & 501,68 \\
\hline 3 & Pertalite & 35 & 41,2 & 41,5 & 41,3 & 41,5 & 41,5 & 41,38 \\
\hline 4 & Minyak Bensin & 35 & 46,3 & 46,5 & 46,3 & 46,4 & 46,6 & 46,42 \\
\hline
\end{tabular}

Tabel 4. Data pengujian waktu alir viskositas zat cair pada suhu $35^{\circ} \mathrm{C}$

\begin{tabular}{|c|c|c|c|c|c|c|c|c|}
\hline \multirow{2}{*}{ No } & \multirow{2}{*}{ Nama Zat Cair } & \multirow{2}{*}{$\begin{array}{c}\text { Volume } \\
(\mathrm{ml})\end{array}$} & \multicolumn{5}{|c|}{ Pengukuran Waktu (s) } & \multirow{2}{*}{$\begin{array}{c}\text { Rerata } \\
\text { Waktu } \\
\text { (s) }\end{array}$} \\
\hline & & & I & II & III & IV & $\mathrm{V}$ & \\
\hline 1 & Air & 35 & 41,9 & 41,9 & 41,6 & 41,5 & 41,6 & 41,70 \\
\hline 2 & Minyak Goreng & 35 & 206,9 & 207,0 & 206,8 & 207,2 & 207,1 & 207,00 \\
\hline 3 & Pertalite & 35 & 40,9 & 40,8 & 41,0 & 41,1 & 40,9 & 40,90 \\
\hline 4 & Minyak Bensin & 35 & 44,4 & 44,5 & 44,4 & 44,3 & 44,5 & 44,42 \\
\hline
\end{tabular}


Tabel 1,2, dan 3 menunjukkan hubungan suhu terhadap viskositas zat cair. Viskositas ketiga zat cair pada ketiga tabel pengujian memberikan nilai yang berbeda-beda. Zat cair yang sama memiliki nilai viskositas yang berbeda pada suhu yang berbeda. Semakin tinggi suhu zat cair, viskositas zat cair semakin kecil. Hal ini terlihat pada hasil pengujian di Tabel 1, 2, dan Tabel 3 dimana nilai viskositas zat cair pada Tabel 1 lebih tinggi daripada nilai vikositas pada Tabel 2 dan Tabel 3, sedangkan suhu untuk pengujian Tabel 1 adalah yang paling rendah. Sebaliknya, nilai viskositas pada Tabel 3 adalah yang paling rendah sedangkan suhupada Tabel 3 adalah yang paling tinggi.

Pengukuran viskositas menggunakan viskometer ostwald alternatif dicobakan pada tiga jenis zat cair, yaitu minyak goreng, pertalite, dan bensin. Hail percobaan ditampilkan melalui Tabel 4, Tabel 5, dan Tabel 6.

Tabel 4. Data Perhitungan viskositas zat cair pada suhu $27^{\circ} \mathrm{C}$

\begin{tabular}{|c|c|c|c|c|}
\hline No & $\begin{array}{l}\text { Nama } \\
\text { Zat } \\
\text { Cair }\end{array}$ & $\begin{array}{l}\text { Pengu- } \\
\text { kuran }\end{array}$ & $\begin{array}{c}\text { Nilai } \\
\text { Viskositas } \\
\left(\mathrm{Ns} / \mathbf{m}^{2}\right)\end{array}$ & $\begin{array}{c}\text { Rata-rata } \\
\text { Nilai } \\
\text { Viskositas } \\
\left(\mathbf{N s} / \mathbf{m}^{2}\right)\end{array}$ \\
\hline \multirow{5}{*}{1} & \multirow{5}{*}{$\begin{array}{l}\text { Minyak } \\
\text { goreng }\end{array}$} & I & 0,01203 & \multirow{5}{*}{0,01200} \\
\hline & & II & 0,01201 & \\
\hline & & III & 0,01197 & \\
\hline & & IV & 0,01196 & \\
\hline & & V & 0,01204 & \\
\hline \multirow[t]{5}{*}{2} & Pertalite & I & $5,7817 \times 10^{-4}$ & \multirow{5}{*}{$5,8243 \times 10^{-4}$} \\
\hline & & II & $5,849 \times 10^{-4}$ & \\
\hline & & III & $5,81 \times 10^{-4}$ & \\
\hline & & IV & $5,796 \times 10^{-4}$ & \\
\hline & & V & $5,850 \times 10^{-4}$ & \\
\hline \multirow[t]{5}{*}{3} & Minyak & I & $8,42 \times 10^{-4}$ & \multirow{5}{*}{$8,475 \times 10^{-4}$} \\
\hline & Bensin & II & $8,53 \times 10^{-4}$ & \\
\hline & & III & $8,473 \times 10^{-4}$ & \\
\hline & & IV & $8,438 \times 10^{-4}$ & \\
\hline & & V & $8,494 \times 10^{-4}$ & \\
\hline
\end{tabular}

Tabel 4 menunjukkan bahwa viskositas minyak goreng lebih tinggi dari pertalite, dan viskositas pertalite lebih tinggi dibandingkan bensin. Ketiga zat cair diukur pada suhu $27^{\circ} \mathrm{C}$. Data viskositas ketiga zat cair ini pada suhu $30^{\circ} \mathrm{C}$ ditampilan pada Tabel 5 .
Tabel 5. Data perhitungan viskositas zat cair pada suhu $30^{\circ} \mathrm{C}$

\begin{tabular}{|c|c|c|c|c|}
\hline No & $\begin{array}{c}\text { Nama } \\
\text { Zat } \\
\text { Cair }\end{array}$ & $\begin{array}{l}\text { Pengu- } \\
\text { kuran }\end{array}$ & $\begin{array}{c}\text { Nilai } \\
\text { Viskositas } \\
\left(\mathrm{Ns} / \mathbf{m}^{2}\right)\end{array}$ & $\begin{array}{c}\text { Rata-rata } \\
\text { Nilai } \\
\text { Viskositas } \\
\left(\mathrm{Ns} / \mathbf{m}^{2}\right)\end{array}$ \\
\hline \multirow{5}{*}{1} & \multirow{5}{*}{$\begin{array}{l}\text { Minyak } \\
\text { goreng }\end{array}$} & I & $7,4680 \times 10^{-3}$ & \multirow{5}{*}{$7,4108 \times 10^{-3}$} \\
\hline & & II & $7,3679 \times 10^{-3}$ & \\
\hline & & III & $7,3371 \times 10^{-3}$ & \\
\hline & & IV & $7,4319 \times 10^{-3}$ & \\
\hline & & $\mathrm{V}$ & $7,4492 \times 10^{-3}$ & \\
\hline \multirow[t]{5}{*}{2} & Pertalite & I & $5,4823 \times 10^{-4}$ & \multirow{5}{*}{$5,4631 \times 10^{-4}$} \\
\hline & & II & $5,4460 \times 10^{-4}$ & \\
\hline & & III & $5,3950 \times 10^{-4}$ & \\
\hline & & IV & $5,4833 \times 10^{-4}$ & \\
\hline & & V & $5,5093 \times 10^{-4}$ & \\
\hline \multirow[t]{5}{*}{3} & Minyak & I & $7,7550 \times 10^{-4}$ & \multirow{5}{*}{$8,475 \times 10^{-4}$} \\
\hline & Bensin & II & $7,6811 \times 10^{-4}$ & \\
\hline & & III & $7,6130 \times 10^{-4}$ & \\
\hline & & IV & $7,7357 \times 10^{-4}$ & \\
\hline & & V & $7,7871 \times 10^{-4}$ & \\
\hline
\end{tabular}

Tabel 5 menunjukkan adanya perbedaan nilai viskositas setelah dinaikkan suhunya sebesar $3^{0} \mathrm{C}$. Hasil perhitungan menunjukkan bahwa nilai viskositas yang diperoleh pada Tabel 5 lebih kecil daripada Tabel 4. Data perhitungan ketiga zat cair pada suhu $35^{\circ} \mathrm{C}$ dapat dilihat pada Tabel 6.

Tabel 6. Data perhitungan viskositas zat cair pada suhu $35^{\circ} \mathrm{C}$

\begin{tabular}{|c|c|c|c|c|}
\hline No & $\begin{array}{l}\text { Nama } \\
\text { Zat } \\
\text { Cair }\end{array}$ & $\begin{array}{l}\text { Pengu- } \\
\text { kuran }\end{array}$ & $\begin{array}{c}\text { Nilai } \\
\text { Viskositas } \\
\left(\mathbf{N s} / \mathbf{m}^{2}\right)\end{array}$ & $\begin{array}{c}\text { Rata-rata } \\
\text { Nilai } \\
\text { Viskositas } \\
\left(\mathbf{N s} / \mathbf{m}^{2}\right)\end{array}$ \\
\hline \multirow{5}{*}{1} & \multirow{5}{*}{$\begin{array}{l}\text { Minyak } \\
\text { goreng }\end{array}$} & I & $2,8528 \times 10^{-3}$ & \multirow{5}{*}{$2,8678 \times 10^{-3}$} \\
\hline & & II & $2,8541 \times 10^{-3}$ & \\
\hline & & III & $2,8720 \times 10^{-3}$ & \\
\hline & & IV & $2,8844 \times 10^{-3}$ & \\
\hline & & V & $2,8761 \times 10^{-3}$ & \\
\hline \multirow[t]{5}{*}{2} & Pertalite & I & $5,4823 \times 10^{-4}$ & \multirow{5}{*}{$5,0694 \times 10^{-4}$} \\
\hline & & II & $5,0279 \times 10^{-4}$ & \\
\hline & & III & $5,0890 \times 10^{-4}$ & \\
\hline & & IV & $5,1137 \times 10^{-4}$ & \\
\hline & & V & $5,0766 \times 10^{-4}$ & \\
\hline \multirow[t]{5}{*}{3} & Minyak & I & $6,8872 \times 10^{-4}$ & \multirow{5}{*}{$6,9234 \times 10^{-4}$} \\
\hline & Bensin & II & $6,9028 \times 10^{-4}$ & \\
\hline & & III & $6,9369 \times 10^{-4}$ & \\
\hline & & IV & $6,9380 \times 10^{-4}$ & \\
\hline & & V & $6,9525 \times 10^{-4}$ & \\
\hline
\end{tabular}

Semakin besar viskositas fluida, semakin sulit fluida untuk mengalir. Hal ini disebabkan karena gerakan partikel cairan yang semakin lambat ketika suhu diturunkan (Putri \& Kasli, 
2017). Hubungan viskositas dan suhu adalah berbanding terbalik. Hal ini juga sesuai dengan hasil penelitian Lubis (2007) yang menyatakan bahwa suhu mempengaruhi laju hantaran kalor hidrolik. Hal ini dipengaruhi oleh perubahan viskositas zat cair. Begitu suhu menurun, viskositas meningkat sehingga laju hantaran hidrolik ikut menurun.

Agar alat ini menjadi alat yang layak untuk mengukur viskositas zat cair, maka harus diperhatikan beberapa faktor yang mempengaruhi pengukuran seperti diameter dari masing-masing ujung tabung buret, ketinggian tabung buret, panjang tabung buret, volume zat cair didalam buret, adanya kehadiran zat lain didalam zat cair, ukuran dan berat molekul zat cair, hubungan antar molekul zat cair serta konsentrasi zat cair.

\section{Kesimpulan dan Saran}

Berdasarkan hasil analisa dan pembahasan dapat disimpulkan bahwa alat yang dibuat dapat digunakan untuk mengetahui viskositas suatu fluida dengan menghitung waktu alir fluida. Terdapat hubungan antara lamanya waktu alir dengan viskositas suatu zat cair, yaitu semakin besar waktu alirnya, maka nilai viskositas dari suatu zat cair tersebut semakin besar. Sebaliknya, semakin kecil waktu alirnya, maka nilai viskositas dari suatu zat cair tersebut akan semakin kecil. Selain itu, juga diperoleh hubungan antara viskositas zat cair dengan suhu, hubungan keduanya yakni berbanding terbalik, yang artinya semakin tinggi suhu zat cair, maka viskositasnya akan semakin kecil. Sebaliknya, semakin rendah suhu zat cair, maka viskositasnya akan semakin besar.

Saat membuat prototipe pengukur viskositas zat cair mestinya memperhatikan beberapa aspek yang dapat menghambat hasil yang diperoleh seperti meminimalisir kemiringan alat. Sebab jika terdapat kemiringan atau tidak tegak lurus, maka hal itu akan mempengaruhi hasil yang didapat, serta harus juga memperhatikan aspek suhu dari zat cair, karena suhu adalah salah satu aspek penting yang mempengaruhi viskositas zat cair.

\section{Daftar Pustaka}

Halliday, David, 2012. Fisika Dasar. Edisi 7 Jilid 1. Erlangga, Jakarta.

Lubis, Kemala Sari, 2007. Aplikasi Suhu dan Aliran Panas Tanah.

Putra, A. S., 2013. Disain dan Komputerisasi Viskometer Kapiler.

Putri, Aiyuni \& Elisa Kasli, 2017. Pengaruh Suhu terhadap Viskositas Minyak Goreng. Prosiding Seminar Nasional MIPA III, ISBN 978-602-50939-0-6.

Rana, Arya Jayeng, 2015. Pengaruh Viskositas Berbagai Minyak Sawit untuk Oli Peredam Shock Absorber Sepeda Motor (Doctoral dissertation, UPT. Perpustakaan Unand).

Ridwan, R., Wiseno, E., \& Suwargo, P. G., 2012. Pembuatan dan Pengujian Viskometer Tabung. Skripsi Program Studi Teknik Informatika.

Samdara, R., Bahri, S., \& Muqorobin, A., 2008. Rancang Bangun Viskometer dengan Metode Rotasi Berbasis Komputer. GRADIEN, 4 (2), 342-348.

Sutiah, S., Firdausi, K. S., \& Budi, W. S., 2008. Studi Kualitas Minyak Goreng dengan Parameter Viskositas dan Indeks Bias.bBerkala Fisika, 11(2), 53-58.

Young, H. D., 2002. Fisika untuk Universitas Jilid I. Erlangga, Jakarta. 